\title{
Incidence and risk factors of low birth weight babies born in Dhulikhel Hospital
}

\author{
S. D. Singh ${ }^{1}$, S. Shrestha ${ }^{1}$, S. B.Marahatta ${ }^{2}$ \\ ${ }^{1}$ Department of Paediatrics, Kathmandu University School of Medical Sciences; ${ }^{2}$ Department of Community Medicine, \\ Kathmandu University School of Medical Sciences, KUSMS, Dhulikhel, Kavre, Nepal.
}

Correspondence to: Srijana Dongol Singh, Department of Paediatrics, Kathmandu University School of Medical Sciences.

Email: docsrijana@yahoo.com

\begin{abstract}
Introduction: WHO defines low birth weight (LBW) as a birth weight less than 2500 grams. Almost a third of the newborn in South East Asia Region is a low birth weight baby. Many risk factors contributing to LBW have been recognized, which in order of importance are low maternal weight, low maternal hemoglobin, low maternal height, primi-parity, adolescent mother and poor or inadequate maternal nutrition during pregnancy. Low birth weight babies have a higher risk of morbidity and mortality than an infant of normal birth weight. The present study was carried out to explore the associated risk factors of low birth weight which will be beneficial to undertake effective measures to reduce the burden of the low birth weight.
\end{abstract}

Methods: This was a hospital based case control study conducted in Dhulikhel hospital, Kavre, Nepal from Jan $1^{\text {st }} 2008$ to $30^{\text {th }}$ May 2010. A total of 401 cases and an equal number of age matched controls were taken to assess the different risk factors of the mother for LBW babies. Ethical approval for the study was taken from KUSMS-Institutional research committee. Data analysis was done using SPSS version 10.0.

Results: Data of $401 \mathrm{LBW}$ and equal number of normal birth weight babies were analyzed. The incidence of LBW in this study was $11.07 \%$. LBW was more common in female $(n=236)$ than in male $(n=165)$ babies. However this difference was statistically insignificant. Among the case and the control group, maternal hemoglobin $(\mathrm{p}<0.001)$, maternal height $(\mathrm{p}<0.001)$, maternal weight gain $(\mathrm{p}<0.0001)$, number of ANC visits $(\mathrm{p}<0.0001)$ were statistically significant. However with regards to ethnicity, nutrition during pregnancy, parity and age of the mother the association were insignificant. Ethnical group, nutrition during pregnancy, age of mother and parity was found to be statically insignificant for LBW

Conclusions: LBW is a common problem of the developing world, which is an important factor for perinatal mortality and morbidity. Maternal height, hemoglobin, total weight gain and ANC visit were found to be the significant risk factors contributing to LBW.

\section{Introduction}

Low birth weight (LBW) is a challenging public health problem. Its high priority stems from the fact that it is the major predictor of infant mortality in developed countries and that it contributes substantially to the overall burden of childhood handicap. Asia has the lowest mean birth weight babies in the world. Almost a third of the newborn in the South East Asia region is low birth weight. Scientifically, in spite of advances in the medical science of pregnancy and delivery, the proportion of LBW births has changed little in the world during the past 30 years. ${ }^{1}$

The incidence of LBW is estimated to be $16 \%$ worldwide, $19 \%$ in the least developed and developing countries and 7 $\%$ in the developed countries. The incidence of LBW is 31 $\%$ in South Asia followed by East and North Africa (15\%), Sub-Saharan Africa (14\%) and East Asia and Pacific $7 \%$ of the total estimated IUGR babies. Asia accounts for $75 \%$ 
and with $20 \%$ and 5 born in Africa and Latin America respectively. In Nepal, the LBW prevalence is relatively high, ranging from $14-32 \%$, as documented from various hospital and community - based studies. ${ }^{2,3}$ In a study done in Nepal, the LBW rate was found to be $27 \%$ out of which term LBW babies constitute $70 \%$ and preterm $30 \% .^{3}$

LBW babies have a higher risk of morbidity and mortality relative to the risk in an infant of normal birth weight. These babies are at an increased risk of asphyxia, hypoglycemia, polycythemia- hyper viscosity, hypothermia. and are more prone to have impaired neurodevelopment and diabetes mellitus in adult life. ${ }^{4}$

The objective of our study was to identify the incidence of LBW in our hospital and the common risk factors associated with LBW babies.

\section{Methods}

This was a hospital based case - control study conducted in Dhulikhel Hospital (Kathmandu University Hospital), Dhulikhel, Kavre, Nepal. The study was conducted from $1^{\text {st }}$ January, 2008 to $30^{\text {th }}$ May, 2010.

The study was done to identify the risk factor of LBW among the babies delivered in Dhulikhel Hospital. Total numbers of 401 cases were taken and equal number of controls $(1: 1)$ were taken. The study population were all the cases who had delivered term low birth weight babies less than $2500 \mathrm{gm}$ and whose mothers had done at least 3 ANC visit in our hospital. For each case, a control (matched in gestational age) who had delivered a term baby of normal birth weight was selected. NBW was considered the cases who had delivered term babies more than $2500 \mathrm{gm}$. Mild anemia is considered for the cases whose haemoglobin is between 8.1 to $11 \mathrm{~g} / \mathrm{dl}$. Moderate anemia is considered for the cases whose haemoglobin is between 5.1 to $8 \mathrm{~g} / \mathrm{dl}$. Severe anemia is considered for the cases whose haemoglobin is less than $5 \mathrm{~g} / \mathrm{dl}$.

Variables like sex of the baby, ethnicity, age of the mother, weight, height and hemoglobin level of the mother, number of ANC visit, mode of delivery and APGAR scores of baby were compared among cases and control group.

Ethical approval was taken from KUSMS-IRC for the study. Informed consent was taken from all the study participants prior to taking information after explaining in detail about the nature of the study. Because most of mothers are unaware of their pre-pregnancy weight, weight within 20 weeks of pregnancy was considered as pre-pregnancy weight. ANC card was used to record the hemoglobin, maternal height, total number of ANC visit and also the total weight gain during pregnancy. The analysis of the data was carried out by using SPSS version 10 .

\section{Results}

During the study period a total of 401 LBW babies were born among 3623 births, the incidence of low birth weight was found to be $11.07 \%$.

Out of 401 low birth weight babies, $58.9 \%(n=236)$ were female and $41.1 \%(n=165)$ were male babies. The result was reverse in control group, where normal birth weight more common in males $(53.1 \%)$ than in females $(46.9 \%)$. However, these differences were statistically insignificant. $(\mathrm{p}=0.057)$

Among the studied mothers $43 \%$ were Brahmins, $20.9 \%$ were Chhetris, $16 \%$ were Newars, $12.7 \%$ were Mongols and $7.2 \%$ were Dalits. There was no statistically significant difference in terms of among the case and the control group. $(\mathrm{p}=0.446)$

Among the studied mothers, the most frequent age group was 21-29 years (Table 1). The mean maternal age among the LBW group was $22.8 \pm 3.9$ years, and in normal group was 23.1 \pm 4.1 years $(\mathrm{p}=0.724)$.

Table 1. Low Birth Weight and variable risk factors

\begin{tabular}{|c|c|c|c|c|c|}
\hline $\begin{array}{l}\text { Age groups of the } \\
\text { mothers }<20\end{array}$ & 125 & 31.2 & 125 & 31.2 & $\begin{array}{l}0.724 \\
\text { (Paired } \\
\text { sample test) }\end{array}$ \\
\hline $21-29$ & 248 & 61.8 & 248 & 61.8 & \\
\hline $30-34$ & 23 & 5.7 & 23 & 5.7 & \\
\hline$\Rightarrow 35$ & 5 & 1.2 & 5 & 1.2 & \\
\hline $\begin{array}{l}\text { Height of the mothers } \\
\text { (in years) }<140\end{array}$ & 16 & 4.0 & 10 & 2.5 & $<0.001^{*}$ \\
\hline $140-150$ & 195 & 48.6 & 70 & 17.5 & \\
\hline$\Rightarrow 150$ & 190 & 47.4 & 321 & 80.0 & \\
\hline $\begin{array}{l}\text { Parity } \\
1\end{array}$ & 242 & 60.3 & 238 & 59.4 & 0.641 \\
\hline $2-4$ & 143 & 35.7 & 151 & 37.7 & \\
\hline$\Rightarrow>4$ & 16 & 4.0 & 12 & 3.0 & \\
\hline $\begin{array}{l}\text { Total maternal weight } \\
\text { gain (in kgs) }<5\end{array}$ & 64 & 16.0 & 1 & 0.2 & $<0.001 *$ \\
\hline $5-10$ & 257 & 64.1 & 119 & 29.7 & \\
\hline$\Rightarrow>10$ & 80 & 20.0 & 281 & 70.1 & \\
\hline $\begin{array}{l}\text { Hemoglobin }(\text { in } \mathrm{gm} / \mathrm{dl}) \\
\text { Severe anemia }(5.1-8)\end{array}$ & 1 & 0.2 & 4 & 1.0 & $<0.001 *$ \\
\hline $\begin{array}{l}\text { Moderate anemia (8.1- } \\
\text { 11) }\end{array}$ & 189 & 47.1 & 116 & 28.9 & \\
\hline$\Rightarrow 11$ & 211 & 52.6 & 281 & 70.1 & \\
\hline $\begin{array}{l}\text { Nutrition } \\
\text { Normal food }\end{array}$ & 311 & 77.6 & 300 & 74.8 & 0.118 \\
\hline Suplement food & 90 & 22.4 & 101 & 25.2 & \\
\hline $\begin{array}{l}\text { ANC visits } \\
3\end{array}$ & 129 & 32.2 & 4 & 1.0 & $<0.001 *$ \\
\hline$>=4$ & 272 & 67.8 & 397 & 99.0 & \\
\hline
\end{tabular}

LBW is common in mother with height range between 140$150 \mathrm{~cm}$ and normal birth weight was common among the 
mother the mother height more than $150 \mathrm{~cm}$. Height was found to be significantly different $(\mathrm{p}<0.001)$ among the case and control group. Among the studied mothers, the most frequent parity was primi group. The mean parity among the LBW group was 1.6 \pm 0.9 , and in normal group was $1.5 \pm 0.7$ $(\mathrm{p}=0.641)$

The maximum number of LBW babies was delivered by mother whose total maternal weight gain during pregnancy was less than $5 \mathrm{~kg}$ in comparison to only 1 case of normal birth weight in mother whose total weight gain is less than $5 \mathrm{Kg}$. The incidence of LBW was seen in those mother with total weight gain is less than $10 \mathrm{Kg}$. By applying Chi square test total maternal weight gain during pregnancy was found to be significantly different $(\mathrm{p}<0.001)$ among the case and control group.

Similarly Hemoglobin level was found to be significantly different $(\mathrm{p}<0.001)$ among the case and control group. Among the studied mother there was no significant different in nutrition between the case and control group. $(p=0.118)$

In the LBW group only $67.8 \%$ of mother had 3 ANC visit in contrast to the mother of normal group, in whom $99 \%$ of mother had 4 or more ANC visits. ANC visit was found to be significantly different $(\mathrm{p}<0.001)$ among the case and control group.

Normal delivery was the most common mode of delivery in both case and control group. The incidence of CS was almost similar in case (14.2\%) and control (15.5\%) group. Mode of delivery was not found to be statistically significant.

\section{Discussion}

Prevalence of LBW (11.07\%) observed in our study is comparable to that observed in the study carried out in Peshawar of Pakisthan and was half that of recent studies (19-23\%) in Lahor and Karachi. ${ }^{5,6}$ The difference in the incidence of LBW might be due to ethnicity and racial differences in Lahor and Karachi compared to Kavre. Another study done by Deswal et al in 1999 from India also found a similar incidence of LBW of about $9.14 \% .^{7}$ The incidence of $\mathrm{LBW}$ in this study is quite low in comparison to that in Dehradun, India where the incidence of LBW was $23.8 \%{ }^{8}$

In our study, of the total LBW, $43 \%$ were Brahmins; $20.9 \%$ were Chhetris; $16 \%$ were Newars; $12.7 \%$ were Mongols and $7.2 \%$ Dalits. Amongst mothers with $\mathrm{Hb}>11 \mathrm{gm} / \mathrm{dl}$, only $52.6 \%$ has LBW, compared to $70.1 \%$ had NBW babies. In mothers with moderate anemia incidence of LBW is almost double in compare to the control group. In our study, the incidence of mild anemia was $47.1 \%$, moderate anemia 0.2 $\%$ and there were no cases of severe anemia.
The DHS of 2006 showed that the incidence of mild anaemia was lower than the present study that was $29.6 \%$ among nulliparous, among primi was $28.2 \%$, with second to third gravida is $29.3 \%$ and grand multipara $30.4 \%$. The incidence of moderate anemia was between $6.4-6.2 \%$. The incidence of moderate anemia is quite similar with the present study that is between $0.3-0.6 \% . .^{9}$ A study in Yemen in 2002 also showed the significant association of anemia with low birth weight, where incidence of anemia was $25.5 \%$ in pregnant women. ${ }^{9}$

Some other study also found a strong relationship between anemia and LBW. The finding were similar with our study where Hemoglobin level was found to be significantly different $(\mathrm{p}<0.001)$ among the case and control groups..$^{10,11}$

Due to the natural decrease in haemoglobin level during pregnancy, the haematocrit measurement should be carried out prior to pregnancy. In the present study, since the prepregnancy haemoglobin levels were not available, the haemoglobin levels were taken from the hospital records which measured the maternal haemoglobin at the time of first ANC visit. It was, thus, not possible to conclude whether the mothers became anaemic at some stage in pregnancy or they were already anaemic before getting pregnant.

Maternal height could affect intrauterine growth through either genetic or environmental mechanism. Part of mother's genetic environment would be passed to the fetus and any deficient in her stature, regardless of its etiology, could impose physical limitations on the growth of the uterus, placenta and fetus. ${ }^{12}$ This study suggests that mothers shorter than $150 \mathrm{~cm}$ of height deliver a higher proportion of LBW babies. The relationship between height and birth weight was found to be significant which was similar to that reported by Kraemer and Trivedi. ${ }^{13,14}$ On the contrary Amin et al report that the relationship between height and birth weight were statistically insignificant. ${ }^{15}$

In our study $16 \%$ of mother with total weight gain less than $5 \mathrm{Kg}$ had LBW while only $0.2 \%$ of mother with less than 5 $\mathrm{Kg}$ weight gain had NBW babies. Those who have gained more than $10 \mathrm{Kg}$ even had incidence of LBW $20 \%$ which might be contributed by genetic predisposition of LBW, maternal height, maternal chronic illness etc. Mother with weight gain more than $10 \mathrm{Kg}$ that contributing $70.1 \%$ had NBW babies. The study suggests that maternal weight gain in pregnancy was significantly associated with birth weight of the babies.

ANC could have a beneficial impact on intra uterine growth or gestational duration either by diagnosis and timely treatment of pregnancy complication or by eliminating or reducing modifiable risk factor. 
In this study, mother having 3 ANC visit had $32.2 \%$ LBW while only $1 \%$ and NBW. Almost $99 \%$ of NBW babies' mother has more than 4 or more ANC visit during their pregnancy. This result was more that that shown by Malik $\mathrm{S}$ et al where they found the incidence of LBW was $25 \%$ in mother who received more than 4 ANC visit. ${ }^{16}$ Similarly another study done at Dehradun India, also shown that the birth weight of newborns was influenced significantly by the number of ANC visit made by the mother. ${ }^{8}$ This study also shown that mothers with one antenatal visit had almost six times higher risk of having a LBW baby in comparison to mothers who had 5 or more antenatal visits.

In the present study incidence of LBW and NBW were similar with the mother's age below 20 years, which was $31.2 \%$. The incidence of LBW was similar to that in rural Rajshahi (2003) where incidence of LBW was $34.3 \%$ in mother less than 20 years. ${ }^{17}$ The incidence of LBW was quite low $1.2 \%$ as compared to the study done by $\mathrm{M} \mathrm{A}$ Ullah et al where incidence of LBW was $40 \% .{ }^{17}$ The statistical analysis showed that the relationship between birth weight and maternal age was insignificant. Study done in Iran also found maternal age to be statistically insignificant among the case and control group. ${ }^{18}$ In the present study APGAR score also found to be statistically significant.

As per our study supplement nutrition was found to be an insignificant factor affecting LBW babies $(\mathrm{p}=0.118)$. As the dietary habit was not thoroughly assessed, the informant bias might have influenced the outcome and this could be a limitation of this study.

\section{Conclusions}

Low birth weight is an important factor for perinatal morbidity and mortality and is a common problem in the developing world. Among the various risk factors the maternal factors like height, hemoglobin, total maternal weight gain, ANC visit and APGAR score of the baby was found to influence the birth weight. Hence, it is important strengthen the existing maternal services at the basic level of community to solve this problem.

\section{References}

1. H.Phung, A. Bauman, T.V.Nguyen, L. Young, M.Tran \& K.Hillman :Risk factors for low birth weight in a socioeconomically disadvantaged population: Parity, marital status, Ethnicity and cigarette smoking .European Journal of Epidemiology 2003;18(3):235-243

2. WHO, Multicenter study on LBW and infant mortality in India, Nepal and Srilanka regional health paper, SEARO 1994; No.25.
3. MIRA. Low Birth Weight prevalence and associated factors in four regions of Nepal. (A multi- hospital based study) UNICEF. June 2000.

4. Stoll BJ, Kliegman RM, high risk infant. In: Behrman RE, Kliegman RM, Jenson HB, editors Nelson textbook of Pediatrics. $17^{\text {th }}$ Edition. Philadelphia: Saunders; 2004: 547-59

5. Namji RS: Distribution of birth weight of hospital born Pakistani infants. J Pak Med Assoc 2000; 50(4): 121-124.

6. Aziz, Billo AG, Samad NJ: Impact of socio-economic condition on prenatal mortality in Karanchi. J Pak Med Assoc 2001;51 (10): 354-60

7. BS Deswal, JV Singh, D Kumar: A study of Risk factors for low birth weight.Indian Journal of community Medicine 1999;24 (3) : 127-131.

8. K.S Negi, S.D Kandpal, M. Kukreti: Epidemiological Factors Affecting Low Birth Weight. JK

9. Abdulwahab M.Makki: Risk factor for low birth weight in Sana's city. Yemen.2002;22:5-6

10. Malhotra M : Maternal and perinatal outcome in varying degrees of anemia. International journal of gynecology and obstetrics. 2002; 9(2):93-100.

11. S.A. Rizvi, J. Hatcher, I. Jehan and R. Qureshi :Maternal risk factors associated with low birth weight in Karachi. Health Journal 2007;13(6)http://www.emro.who.int/ emhj/1306/13_6_2007_1343_1352.pd

12. Karmer MS. Determinants of Low Birth weight. Bull WHO 1987; 65-37

13. Kraemer MS. Determinants of delivering low birth weight . Methodology assessment and meta analysis Bull WHO Org 1987;5: 663-737.

14. Trivedi CR, Mavalankar DV: Epidemiology of low birth weight in Ahemdabad. Int J Paed 1986;53: 795- 800.

15. Amin N, Ab et R, Sampathkumar V: Maternal risk factors associated with low birth weight .Ind J Paed 1993;60: 269-74.

16. Antonisomy B, Rao P.S.S, Sivram M: Changing scenario of birth weight in South India. Indian Pediatric 1999;31: 931-937.

17. MA Ullah, M J Haque, H A Hafez Merina Khanam: Biological weight in Rural Rajshahi .2003; 16 (2): 50-53.

18. Shiva Rafati: Maternal determinants of giving birth to low birth weight neonates.2005;8(4): 277-281 